\title{
Concordance of Gleason grading with three-dimensional ultrasound systematic biopsy and biopsy core pre-embedding
}

\section{Citation for published version (APA):}

van der Aa, A. A. M. A., Mannaerts, C. K., van der Linden, H., Gayet, M., Schrier, B. P., Mischi, M., Beerlage, H. P., \& Wijkstra, H. (2018). Concordance of Gleason grading with three-dimensional ultrasound systematic biopsy and biopsy core pre-embedding. World Journal of Urology, 36(6), 863-869. https://doi.org/10.1007/s00345-0182209-7

\section{Document license: \\ TAVERNE}

DOI:

10.1007/s00345-018-2209-7

Document status and date:

Published: 01/06/2018

\section{Document Version:}

Publisher's PDF, also known as Version of Record (includes final page, issue and volume numbers)

\section{Please check the document version of this publication:}

- A submitted manuscript is the version of the article upon submission and before peer-review. There can be important differences between the submitted version and the official published version of record. People interested in the research are advised to contact the author for the final version of the publication, or visit the DOI to the publisher's website.

- The final author version and the galley proof are versions of the publication after peer review.

- The final published version features the final layout of the paper including the volume, issue and page numbers.

Link to publication

\section{General rights}

Copyright and moral rights for the publications made accessible in the public portal are retained by the authors and/or other copyright owners and it is a condition of accessing publications that users recognise and abide by the legal requirements associated with these rights.

- Users may download and print one copy of any publication from the public portal for the purpose of private study or research.

- You may not further distribute the material or use it for any profit-making activity or commercial gain

- You may freely distribute the URL identifying the publication in the public portal.

If the publication is distributed under the terms of Article 25fa of the Dutch Copyright Act, indicated by the "Taverne" license above, please follow below link for the End User Agreement:

www.tue.nl/taverne

Take down policy

If you believe that this document breaches copyright please contact us at:

openaccess@tue.nl

providing details and we will investigate your claim. 


\title{
Concordance of Gleason grading with three-dimensional ultrasound systematic biopsy and biopsy core pre-embedding
}

\author{
Anouk A. M. A. van der Aa ${ }^{1,3} \cdot$ Christophe K. Mannaerts ${ }^{4} \cdot$ Hans van der Linden ${ }^{2} \cdot$ Maudy Gayet $^{1,3} \cdot$ Bart Ph. Schrier $^{1}$. \\ Massimo Mischi ${ }^{3} \cdot$ Harrie P. Beerlage ${ }^{1,3} \cdot$ Hessel Wijkstra ${ }^{3,4}$
}

Received: 13 November 2017 / Accepted: 24 January 2018 / Published online: 1 February 2018

(c) Springer-Verlag GmbH Germany, part of Springer Nature 2018

\begin{abstract}
Purpose To determine the value of a three-dimensional (3D) greyscale transrectal ultrasound (TRUS)-guided prostate biopsy system and biopsy core pre-embedding method on concordance between Gleason scores of needle biopsies and radical prostatectomy (RP) specimens.

Methods Retrospective analysis of prostate biopsies and subsequent RP for PCa in the Jeroen Bosch Hospital, the Netherlands, from 2007 to 2016. Two cohorts were analysed: conventional 2D TRUS-guided biopsies and RP (2007-2013, $n=266)$ versus 3D TRUS-guided biopsies with pre-embedding $(2013-2016, n=129)$. The impact of 3D TRUS-guidance with preembedding on Gleason score (GS) concordance between biopsy and RP was evaluated using the $\kappa$-coefficient. Predictors of biopsy GS 6 upgrading were assessed using logistic regression models.

Results Gleason concordance was comparable between the two cohorts with a $\kappa=0.44$ for the 3D cohort, compared to $\kappa=0.42$ for the 2D cohort. 3D TRUS-guidance with pre-embedding, did not significantly affect the risk of biopsy GS 6 upgrading in univariate and multivariate analysis.

Conclusions 3D TRUS-guidance with biopsy core pre-embedding did not improve Gleason concordance. Improved detection techniques are needed for recognition of low-grade disease upgrading.
\end{abstract}

Keywords Prostatic neoplasms $\cdot$ Neoplasm grading $\cdot$ Biopsy $\cdot$ Prostatectomy $\cdot$ Three-dimensional imaging $\cdot$ Tissue embedding

Anouk A. M. A. van der Aa and Christophe K. Mannaerts have contributed equally to this manuscript.

Electronic supplementary material The online version of this article (https://doi.org/10.1007/s00345-018-2209-7) contains supplementary material, which is available to authorized users.

Anouk A. M. A. van der Aa

A.v.d.Aa@jbz.nl

Christophe K. Mannaerts

C.k.Mannaerts@amc.uva.nl

Hans van der Linden

H.v.d.Linden@jbz.nl

Maudy Gayet

M.Gayet@jbz.nl

Bart Ph. Schrier

B.Schrier@jbz.nl

Massimo Mischi

M.Mischi@tue.nl

Harrie P. Beerlage

H.Beerlage@jbz.nl

Abbreviations
$\begin{array}{ll}\text { aOR } & \text { Adjusted odds ratio } \\ \text { BCR } & \text { Biochemical recurrence } \\ \text { bGS } & \text { Biopsy Gleason score } \\ \text { CI } & \text { Confidence interval }\end{array}$

Hessel Wijkstra

H.Wijkstra@tue.nl

1 Department of Urology, Jeroen Bosch Hospital, Post office box 90153, $5200 \mathrm{ME}$ 's-Hertogenbosch, The Netherlands

2 Department of Pathology, Jeroen Bosch Hospital, 's-Hertogenbosch, The Netherlands

3 Department of Electrical Engineering, Eindhoven University of Technology, Eindhoven, The Netherlands

4 Department of Urology, AMC University Hospital, Amsterdam, The Netherlands 


$\begin{array}{ll}\text { DRE } & \text { Digital rectal examination } \\ \text { GS } & \text { Gleason score } \\ \text { IQR } & \text { Interquartile range } \\ \text { mpMRI } & \text { Multiparametric magnetic resonance imaging } \\ \text { OR } & \text { Odds ratio } \\ \text { PCa } & \text { Prostate cancer } \\ \text { pGS } & \text { Prostatectomy Gleason score } \\ \text { PSA } & \text { Prostate-specific antigen } \\ \text { RP } & \text { Radical prostatectomy } \\ \text { TRUS } & \text { Transrectal ultrasound } \\ \text { 3D } & \text { Three dimensional } \\ \text { 2D } & \text { Two dimensional }\end{array}$

\section{Introduction}

Biopsy Gleason score (bGS) is an important prognostic tool and one of the key factors used to stratify patients with prostate cancer $(\mathrm{PCa})$ into risk groups and direct clinical decision-making [1-3]. The bGS informs treatment decisions in active surveillance (AS) and radiation therapy, including eligibility for brachytherapy, need for pelvic node irradiation and use of androgen deprivation [4, 5]. It is also a key component of preoperative nomograms assessing the risk of disease recurrence and need for extended pelvic lymph node dissection in radical prostatectomy (RP) treatment $[6,7]$. Accurate bGS matching the true underlying tumour pathology is, therefore, of utmost importance. Unfortunately, several studies have demonstrated poor concordance between bGS with conventional systematic two-dimensional (2D), greyscale transrectal ultrasound (TRUS)-guided biopsies and radical prostatectomy Gleason score (pGS) with Gleason score (GS) upgrading ranging from 30 to $40 \%$ [8-10]. Current data suggest that patients with $\mathrm{PCa}$ upgrading from bGS of 6 to a pGS of 7a do not share the same detrimental outcome (PCa death or Biochemical Recurrence) as men without upgrading $[11,12]$. As a result, bGS upgrading is concerning and improved diagnostic confidence is needed as significant numbers of clinically significant $\mathrm{PCa}$ are not accurately identified using the conventional $2 \mathrm{D}$ greyscale TRUS-guided biopsy scheme. Although incorporation of PCa imaging modalities like multiparametric magnetic resonance imaging (mpMRI) and new sonographic modalities with subsequent targeted biopsies have demonstrated improved prediction of final pathology, questions remain whether there are no accessible tools to the community in the large for improved pathology concordance [13-15].

Three-dimensional (3D) TRUS-guided biopsy offers the ability to accurately register the biopsy needle tract location within the prostate allowing for a better biopsy core distribution during TRUS-guided biopsy while biopsy processing with pre-embedding methods lead to significantly larger and non-fragmentized biopsy cores [16-18]. Two studies comparing detection rates of $\mathrm{PCa}$ with the systematic 3D TRUS-guided biopsy and conventional 2D TRUS-guided biopsy reported contradictory results while one study demonstrated higher frequencies of PCa diagnosis with a biopsy pre-embedding method [19-21]. Their influence on accurate prediction of final pathology following prostatectomy, however, is still unclear. In the current study, we investigated the value of 3D TRUS-guidance and biopsy core pre-embedding on concordance between bGS and pGS compared to conventional 2D TRUS-guidance in a consecutive cohort of men undergoing systematic prostate biopsies and subsequent RP.

\section{Materials and methods}

\section{Study population}

Between January 2007 and February 2016, 2171 men underwent prostate biopsy at our institution with 1072 (49\%) of these men positive for PCa on biopsy. We performed a retrospective cohort study containing all men $(n=395)$ who underwent both prostate biopsy and subsequent RP. Systematic biopsy with 2D greyscale TRUS-guidance and subsequent RP was performed from January 2007 up to November 2013 (2D TRUS cohort) while systematic biopsy with 3D greyscale TRUS-guidance and biopsy core pre-embedding and subsequent RP was performed from September 2013 up to February 2016 (3D TRUS cohort). Patients eligible for analysis were divided into these two cohorts. Patient files were consulted and collected data included relevant preoperative and postoperative characteristics, biopsy procedure and pathology results with no exclusion of patients. All patients had a biopsy-proven clinical diagnosis of $\mathrm{PCa}$ preoperatively.

\section{Biopsy protocols}

\section{D TRUS cohort protocol}

A BK medical ultrasound machine (type 2202) and BK medical sidefire probe (type $8808,6-10 \mathrm{MHz}$ ) were used. A 12-core biopsy protocol was performed consisting of 2 biopsies of each base, mid and apex in the peripheral zone on both sides. Biopsy cores were placed in two formalinfilled vials, each vial containing 6 floating free cores of one prostate lobe. Prostate cores were submitted to the hospital pathology lab for processing and examination.

\section{D TRUS cohort protocol}

Protocol-wise the same, the 3D greyscale TRUS system (Navigo $^{\mathrm{TM}}$ workstation, UC-care Medical Systems, Yokneam, Israel) was incorporated with 2D ultrasound 
images transferred and displayed on the 3D screen. After prostate volume measurements, planimetry was done with the outline of the prostate border manually traced and recorded on a slice-by-slice basis where after a 3D model of the prostate was displayed (as shown in the animation Online Resource 1). The 12-core biopsy protocol was performed with tracking, displaying and recording of biopsy needle trajectory locations in real time using an electromagnetic system. Thus, the 3D system was not used to increase the biopsy core load, i.e. perform a mapping biopsy based on the real-time visual coverage of the different taken biopsy cores in the prostate gland during the biopsy procedure. Biopsy cores were processed using the semi-automated prostate biopsy core pre-embedding method (SmartBx ${ }^{\mathrm{TM}}$ device, UCcare Medical Systems, Yokneam, Israel). Biopsy cores of each sampling site (apex, mid and base on both sides) were fixed onto six different cassettes, with a designed membrane to which the cores stay attached throughout pathology lab processing, and placed in two formalin-filled vials (as shown in the animation Online Resource 2). Each vial contained the 3 cassettes with two cores of each different sampling site of one prostate lobe. Each cassette was separately processed and examined at the same hospital pathology lab.

\section{Histopathology}

Pathologic analyses of biopsies and prostatectomy specimens were all performed by pathologists at our institution. Haematoxylin-eosin (HE) staining and immunohistochemistry (IHC) with basal cell markers was performed. For biopsies, number of cores per vial, length of biopsy cores, number of positive biopsy cores and tumour volume per lobe were obtained.

All RP specimens were formalin-fixed, paraffin-embedded and cut in 3-5-mm transverse sections.

For RP, prostate weight, $\mathrm{pT}$ stage, $\mathrm{pN}$ stage and margin status were obtained. GSs were determined according to the International Society of Urological Pathology (ISUP) consensus recommendations [22, 23]. Primary Gleason pattern and highest grade Gleason pattern defined the GS for prostate needle biopsies whereas GS for RP was defined on primary and secondary Gleason patterns with tertiary pattern reported if present. The biopsy and RP specimens were originally reported by multiple pathologists at our institution. Biopsy and RP pathology reports with lacking or insufficient data considering Gleason pattern $(n=36)$ were re-reviewed by one dedicated genito-urinary pathologist (HvdL) for the purpose of this study.

\section{Statistical analysis}

Statistical analyses were performed using SPSS Statistics $23.0^{\circledR}$. Descriptive statistics were used to summarize patient characteristics. Continuous variables were presented with median and interquartile ranges (IQR) with the Mann-Whitney $U$ test used to assess differences. GS (bGS and pGS) were grouped as $\leq 6,7 \mathrm{a}(3+4=7), 7 \mathrm{~b}$ $(4+3=7)$ and $8-10$. In cases with multiple, GS different, tumour foci, the highest grade tumour was used for this analysis. Upgrading and downgrading were defined as an increase or decrease, respectively, from one GS group to another. Tertiary pattern on radical prostatectomy did not define a Gleason upgrade or downgrade for statistical analysis. The coefficient of agreement $(\kappa)$ was used to evaluate the concordance between GS in needle biopsies and RP. The $\kappa$ coefficient can range from $\leq 0$ (no agreement) to 1 (excellent agreement) and measures agreement between discrete variables considering chance agreement. Candidate predictors for bGS 6 upgrading were evaluated in univariate and multivariate logistic regression analyses. A $p<0.05$ was considered statistically significant.

\section{Results}

Between January 2007 and February 2016, 395 patients underwent prostate biopsy and subsequent RP at our institution. 266 of these patients $(67.3 \%)$ underwent prostate biopsy in the 2D TRUS cohort compared to 129 patients $(32.7 \%)$ in the 3D TRUS cohort.

\section{Patient and pathological characteristics}

Characteristics of both biopsy cohorts are shown in Online Resource 3. Median age at biopsy was higher in the 3D TRUS cohort (64 vs. 62 years, $p=0.013$ ). Prebiopsy PSA, clinical T-stage, TRUS prostate volume, hypoechoic lesion on TRUS and EAU risk classification group did not differ significantly between both groups.

The biopsy session type and number of biopsy cores taken per session were comparable between groups, while biopsy sessions in the 3D TRUS cohort were performed more often by an experienced operator (63.6 vs. $50.8 \%, p=0.016)$. Fragmentation of cores occurred less often in the 3D TRUS cohort ( 4.7 vs. $33.8 \%, p<0.001)$, while median length of biopsy cores (16.0 vs. $12.5 \mathrm{~mm}$, $p<0.001)$ and the ratio positive cores of total cores taken per session ( 0.36 vs. $0.33, p=0.005)$ in the 3D TRUS cohort was higher. Gleason scores from both biopsy and RP specimens were different in both cohorts with less bGS 6 (49.6 vs. $70.7 \%, p<0.001)$ and pGS 6 (33.3 vs. $46.2 \%$, $p<0.005)$ in the 3D TRUS cohort. The interval from biopsy to RP, pathologic T-stage and surgical margin status did not differ. 


\section{Gleason score concordance}

Results of Gleason score concordance in the 2D TRUS cohort and 3D TRUS cohort are illustrated in Fig. 1 and summarized in Table 1. For the 2D TRUS cohort, $64.3 \%$ had an equal GS on biopsy and RP, $30.1 \%$ had Gleason upgrading on RP and 5.6\% had Gleason downgrading on RP. The results in the 3D TRUS cohort were 62.0, 27.1 and $10.9 \%$ for equal GS, Gleason upgrading on RP and Gleason downgrading on RP, respectively $(p=0.170)$. The $\kappa$ for Gleason concordance were comparable between the two cohorts with a $\kappa=0.44$ (95\% CI $0.33-0.56)$ for the 3D TRUS cohort, compared to $\kappa=0.42$ (95\% CI $0.33-0.50)$ for the 2D TRUS cohort indicating moderate strength of agreement.
Fig. 1 Gleason score assignment between both study cohorts. Gleason assignment: percentages in the graph present Gleason assignment per category (correct, upgraded on $\mathrm{RP}$, downgraded on RP). $2 D$ two-dimensional, $3 D$ threedimensional, TRUS transrectal ultrasound, $R P$ radical prostatectomy. Dagger, $p$ value: comparison of overall Gleason assignment between both cohorts with a $\chi^{2}$ test

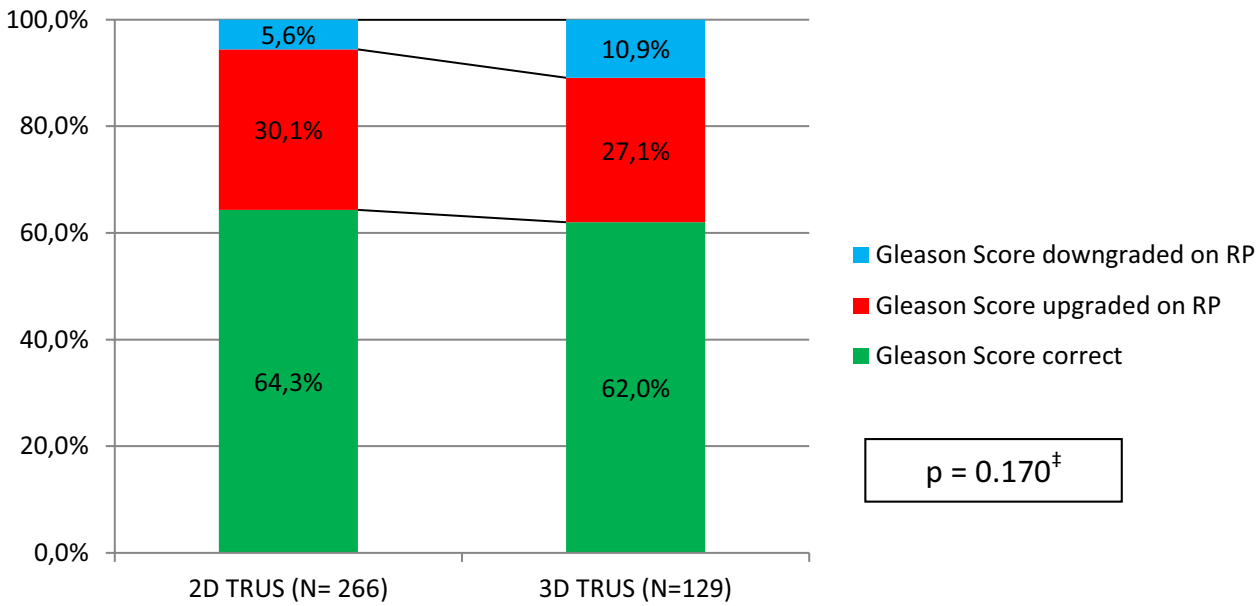

Table 1 Gleason score concordance between biopsy Gleason score and pathology Gleason score

\begin{tabular}{|c|c|c|c|c|c|}
\hline \multicolumn{6}{|c|}{ a. Overall concordance between bGS and pGS for the whole patient cohort } \\
\hline \multirow[b]{2}{*}{ bGS } & \multicolumn{5}{|l|}{ pGS } \\
\hline & 6 & $7 a$ & $7 \mathrm{~b}$ & $8-10$ & Total \\
\hline $6, \mathrm{n}(\%)$ & $155(61.5)$ & $64(25.4)$ & $23(9.1)$ & $10(4.0)$ & $252(100)$ \\
\hline $7 a, n(\%)$ & $6(7.7)$ & $57(73.1)$ & $12(15.4)$ & $3(3.8)$ & $78(100)$ \\
\hline $7 \mathrm{~b}, \mathrm{n}(\%)$ & $3(12.5)$ & $7(29.2)$ & $11(45.8)$ & $3(12.5)$ & $24(100)$ \\
\hline $8-10, \mathrm{n}(\%)$ & $2(4.9)$ & $7(17.1)$ & $4(9.8)$ & $28(68.3)$ & $41(100)$ \\
\hline Total & 166 & 135 & 50 & 44 & $\begin{array}{l}395 \\
(\kappa=0.44,95 \% \mathrm{Cl}: 0.37-0.50)\end{array}$ \\
\hline \multicolumn{6}{|c|}{ b. Concordance between bGS and pGS for the 3D TRUS cohort } \\
\hline \multirow[b]{2}{*}{ bGS } & \multicolumn{5}{|l|}{ pGS } \\
\hline & 6 & $7 a$ & $7 \mathrm{~b}$ & $8-10$ & Total \\
\hline 6 & $38(59.4)$ & $20(31.3)$ & $4(6.3)$ & $2(3.1)$ & $64(100)$ \\
\hline $7 a$ & $2(5.3)$ & $29(76.3)$ & $7(18.4)$ & 0 & $38(100)$ \\
\hline $7 \mathrm{~b}$ & $1(11.1)$ & $3(33.3)$ & $3(33.3)$ & $2(22.2)$ & $9(100)$ \\
\hline $8-10$ & $2(11.1)$ & $5(27.8)$ & $1(5.6)$ & $10(55.6)$ & $18(100)$ \\
\hline Total & 43 & 57 & 15 & 14 & $\begin{array}{l}129 \\
(\kappa=0.44,95 \% \mathrm{Cl}: 0.33-0.56)\end{array}$ \\
\hline \multicolumn{6}{|c|}{ c. Concordance between bGS and pGS for the 2D TRUS cohort } \\
\hline \multirow[b]{2}{*}{ bGS } & \multicolumn{5}{|l|}{ pGS } \\
\hline & 6 & $7 a$ & $7 \mathrm{~b}$ & $8-10$ & Total \\
\hline 6 & $117(62.2)$ & $44(23.4)$ & $19(10.1)$ & $8(4.3)$ & $188(100)$ \\
\hline $7 a$ & $4(10.0)$ & $28(70.0)$ & $5(12.5)$ & $3(7.5)$ & $40(100)$ \\
\hline $7 \mathrm{~b}$ & $2(13.3)$ & $4(26.7)$ & $8(53.3)$ & $1(6.7)$ & $15(100)$ \\
\hline $8-10$ & 0 & $2(8.7)$ & $3(13.0)$ & $18(78.3)$ & $23(100)$ \\
\hline Total & 123 & 78 & 35 & 30 & $\begin{array}{l}266 \\
(\mathrm{k}=0.42,95 \% \mathrm{Cl}: 0.33-0.50)\end{array}$ \\
\hline
\end{tabular}

$2 D$ two-dimensional, $3 D$ three-dimensional, TRUS transrectal ultrasound, $b G S$ biopsy Gleason score, $p G S$ pathology Gleason score Colour indications: Green: GS equal between biopsy and RP, Red: GS upgrading at RP, Blue: GS downgrading at RP 


\section{Biopsy Gleason score 6 upgrading}

The clinical and pathological characteristics of bGS 6 patients with and without GS upgrading are summarized in Online Resource 4. bGS 6 patients with GS upgrading were significantly older (median age in years; 65 vs. 62 , $p=0.002$ ), had higher prebiopsy PSA (median PSA in $\mathrm{ng} / \mathrm{mL} ; 8.9$ vs. $7.4, p=0.001$ ) and more often a palpable tumour on DRE (clinical T-stage; $\geq \mathrm{T} 2 ; 44.8 \%$ vs. $21.4 \%$, $p<0.001) .4$ of 23 patients (17.4\%) that met PRIAS-study AS criteria had a GS upgrading (all pGS $3+4=7$ ). bGS 6 patients with upgrading had more positive cores per session (4.0 vs. 3.0, $p<0.001$ ) while biopsy method did not differ (2D TRUS cohort: $37.8 \%$ vs. 3D TRUS cohort: $40.6 \%$, $p=0.685$ ). bGS 6 patients with GS upgrading had higher pathological T-stages ( $\geq$ pT3; 25.2 vs. $5.8 \%, p<0.001)$, more often positive surgical margins ( 34.0 vs. $21.9 \%$, $p=0.035)$ and more often biochemical recurrence after RP (24.7 vs. $8.2 \%, p<0.001$ ).

Online Resource 5 shows the effect of potential preoperative predictors for upgrading from bGS 6 to a higher pGS. On multivariate analysis higher prebiopsy serum PSA level, palpable clinical T-stage and a higher amount of total positive biopsy cores per session were associated with a higher risk of bGS 6 upgrading (PSA; aOD: 1.36 (95\% CI 1.02-1.81), $p=0.039$, clinical T-stage; aOD: 2.10 (95\% CI $1.14-3.87), p=0.018$ and total positive biopsy cores; aOD: 1.15 (95\% CI 1.02-1.29), $p=0.020$ ). The biopsy method, 2D TRUS or 3D TRUS with pre-embedding, did not significantly affect the risk of bGS 6 upgrading in univariate and multivariate analyses (aOD: 1.35 (95\% CI 0.63-2.92), $p=0.444$ ). Further multivariate subanalyses (bGS 6 to GS $7 \mathrm{~b}$ or higher) were not performed due to limited number of events.

\section{Discussion}

The ability to accurately register the biopsy needle tract location using 3D TRUS-guidance with pre-embedding, allowing for a presumably better biopsy core distribution and significantly larger and non-fragmentized biopsy cores did not result in better GS concordance. The $\kappa$ for Gleason concordance were comparable between the two cohorts and the 3D cohort was not associated with a lower risk of bGS 6 upgrading. The Gleason concordance results of this study, with approximately 29\% GS upgrading, are in line with previous published literature on this topic. It demonstrates that systematic prostate biopsy even under optimal imaging guidance and a standardized pathology processing system fails to match the true underlying tumour pathology $[8,9,24,25]$. Quintana et al. recently demonstrated that their saturation biopsy scheme (median of 20 cores) also did not result in better final pathology prediction compared to a 12-core biopsy scheme. High Gleason grades were often missed because of anatomic locations difficult to biopsy and/or out of the systematic biopsy grid [26]. The intrinsic limitation of 2D TRUS-guided biopsy due to sampling error of common biopsy grid locations, which our 3D TRUS-guidance tends to improve with visually better biopsy core distribution, only occurred in one-third of their patients with GS upgrading. Moreover, Kim et al. demonstrated that besides sampling error, prostate tumour biology also plays an important role in GS upgrading [27]. By including only patients that underwent subsequent RP after their prostate biopsy proved $\mathrm{PCa}$ we do not expect that cancer maturation in the presurgical period played a role in the upgrading of bGS. Moreover, there was no significant difference in the interval from biopsy to RP in days between both cohorts. Regardless of the above-mentioned explanations, the significantly larger, non-fragmentized, biopsy core lengths in the 3D cohort neither resulted in higher concordance rates. Öbek et al. demonstrated that higher biopsy core length was associated with an increased PCa detection rate [28]. Their suggested cutoff length of greater than $11.9 \mathrm{~mm}$ for quality assurance, although aimed at PCa detection, could explain the absence of GS concordance improvement with our preembedding method. After all, the median length in the 2D cohort of $12.5 \mathrm{~mm}$ indicates that the majority of the conventional biopsy sessions already met the necessary biopsy length quality insurance.

In line with previous studies, higher prebiopsy serum PSA, palpable clinical T-stages and more biopsy cores with cancer were significantly associated with bGS 6 upgrading $[9,24-26]$ supporting the use of these variables as selection criteria for AS [5]. There are limitations to the present study. First of all, this is a single-institution, retrospective study with two cohorts that differ in study time period thereby introducing the risk of selection bias and possible time specific factors like Gleason score reclassification potentially influencing GS concordance rates. Second, biopsy and RP GSs were given by multiple pathologists. Interobserver variability and pathologist experience in Gleason grading have been documented and could have influenced GS concordance results [29, 30]. Nonetheless, all Gleason scoring was performed in one institution according to the ISUP recommendations and pathology reports with insufficient data considering Gleason pattern were re-reviewed by one dedicated genito-urinary pathologist [22, 23]. As such, our pathologic data reflect the clinical practice of most practicing urologist. Third, both cohorts differed significantly in biopsy and pathology Gleason scores with the 3D cohort containing substantially less GS 6 disease. Although this paucity of low-risk patients in the 3D cohort undergoing prostatectomy reflects the nationwide shift towards AS, it does limit comparison of both cohorts for Gleason concordance and 
generalizability of the results. Fourth, biopsies were performed by operators with different levels of experience potentially influencing PCa detection results. However, for this study we did not find any association between biopsy operator experience and GS upgrading on RP. Last, tertiary pattern was not used to measure GS concordance. The tertiary pattern of the RP was reported with increasing frequency in recent years $(2.6 \%$ in the 2D cohort vs. $14.7 \%$ in the $3 \mathrm{D}$ cohort) introducing heterogeneity when incorporating this pattern into statistical analysis. Moreover, there are no specific criteria or definitions for reporting tertiary pattern, although the presence of a higher tertiary pattern is significantly linked to unfavourable tumour features, with recent ISUP consensus paper on Gleason Grading postponing suggestions on the integration of the tertiary pattern [23, $31,32]$.

Although our study did not demonstrate a differences in Gleason score concordance using 3D TRUS guidance and pre-embedding there are possible other applications for these techniques. 3D stored biopsy models of previous biopsy sessions in combination with integrated pathology biopsy core results could, for example, be used to define adequate sample sites of interest in prior negative patients and patients in active surveillance.

Our results strengthen the previously published literature on the poor concordance of systematic biopsy GS and RP GS. In view of the fact that patients with bGS 6 upgrading tend to have unfavourable disease outcome, physicians and patients need to be cognizant of these limitations so that well-informed decision-making can be made. Recognition of pre-operative variables associated with Gleason upgrading whether or not incorporated in a nomogram is a first important step [25]. PCa imaging modalities, accurately guiding biopsies to tumour-suspicious lesions, for now combined with systematic biopsy for the best concordance, however, offers greater potential and should be further adopted and refined [13-15].

\section{Conclusion}

3D greyscale TRUS-guidance with biopsy core pre-embedding did not allow for prediction of final prostate pathology with greater accuracy than that of conventional 2D TRUSguidance and biopsy processing. Patients with upgrading of bGS 6 disease are at greater risk of adverse pathologic features and BCR emphasizing the need for recognition of low-grade disease upgrading and supporting the need for improved detection techniques.

Author contributions Project development: AAMAA, MG, CKM. Data collection or management: CKM, AAMAA, MG. Data analysis: CKM, AAMAA, MG. Manuscript writing: AAMAA, CKM.
Manuscript editing: HL, HPB, BPhS, MM, HW. Other: HL revised necessary pathology.

\section{Compliance with ethical standards}

Conflict of interest All authors declare that they have no conflict of interests.

Ethics approval The ethical committee of the Jeroen Bosch Hospital gave ethical approval for this study with a non-WMO declaration.

\section{References}

1. Albertsen PC, Hanley JA, Fine J (2013) 20-year outcomes following conservative management of clinically localized prostate cancer. JAMA 293(17):2095-2101

2. D'Amico AV, Whittington R, Malkowicz SB, Schultz D, Blank $\mathrm{K}$, Broderick GA et al (1998) Biochemical outcome after radical prostatectomy, external beam radiation therapy, or interstitial radiation therapy for clinically localized prostate cancer. JAMA 280(11):969-974

3. Vira MA, Guzzo T, Heitjan DF, Tomaszewski JE, D'Amico A, Wein AJ et al (2008) Is the biopsy Gleason score important in predicting outcomes for patients after radical prostatectomy once the pathological Gleason score is known? BJU Int 101(10):1232-1236

4. Mottet N, Bellmunt J, Bolla M, Briers E, Cumberbatch MG, De Santis M et al (2016) EAU-ESTRO-SIOG guidelines on prostate cancer. Part 1: screening, diagnosis, and local treatment with curative intent. Eur Urol 71(4):1-12. http://www.ncbi.nlm.nih.gov/ pubmed $/ 27568654$

5. Bul M, Zhu X, Valdagni R, Pickles T, Kakehi Y, Rannikko A et al (2013) Active surveillance for low-risk prostate cancer worldwide: The PRIAS study. Eur Urol 63:597-603

6. Kattan M, Eastham J, Stapleton A, Wheeler T, Scardino P (1998) A preoperative nomogram for disease recurrence following radical prostatectomy for prostate cancer. J Natl Cancer Inst 90(10):766-771

7. Briganti A, Larcher A, Abdollah F, Capitanio U, Gallina A, Suardi $\mathrm{N}$ et al (2012) Updated nomogram predicting lymph node invasion in patients with prostate cancer undergoing extended pelvic lymph node dissection: the essential importance of percentage of positive cores. Eur Urol 61(3):480-487

8. Cohen MS, Hanley RS, Kurteva T, Ruthazer R, Silverman ML, Sorcini A et al (2008) Comparing the Gleason prostate biopsy and Gleason prostatectomy grading system: the Lahey Clinic Medical Center experience and an international meta-analysis. Eur Urol 54(2):371-381

9. Kvåle R, Møller B, Wahlqvist R, Fosså SD, Berner A, Busch C et al (2009) Concordance between Gleason scores of needle biopsies and radical prostatectomy specimens: a population-based study. BJU Int 103(12):1647-1654

10. Epstein JI, Feng Z, Trock BJ, Pierorazio PM (2012) Upgrading and downgrading of prostate cancer from biopsy to radical prostatectomy: incidence and predictive factors using the modified Gleason grading system and factoring in tertiary grades. Eur Urol 61(5):1019-1024

11. Boehm K, Leyh-Bannurah S-R, Rosenbaum C, Budäus L, Graefen M, Haferkamp A et al (2017) Impact of preoperative risk on metastatic progression and cancer specific death in patients with adverse pathology at radical prostatectomy. Eur Urol Suppl 16(3):e26-e28 
12. Imnadze M, Sjoberg DD, Vickers AJ (2016) Adverse pathologic features at radical prostatectomy: effect of preoperative risk on oncologic outcomes. Eur Urol 69(1):143-148

13. Le JD, Stephenson S, Brugger M, Lu DY, Lieu P, Sonn GA et al (2014) Magnetic resonance imaging-ultrasound fusion biopsy for prediction of final prostate pathology. J Urol 192(5):1367-1373

14. Borkowetz A, Platzek I, Toma M, Renner T, Herout R, Baunacke $M$ et al (2016) Direct comparison of multiparametric magnetic resonance imaging (MRI) results with final histopathology in patients with proven prostate cancer in MRI/ultrasonographyfusion biopsy. BJU Int 118(2):213-220

15. Boehm K, Tennstedt P, Beyer B, Schiffmann J, Beckmann A, Michl U et al (2015) Additional elastography-targeted biopsy improves the agreement between biopsy Gleason grade and Gleason grade at radical prostatectomy. World J Urol. 34(6):805-810

16. Cool DW, Connolly MJ, Eagleson R, Amann J, Romagnoli C, Romano WM (2010) Repeat prostate biopsy accuracy: simulatorbased comparison of two- and three-dimensional transrectal US modalities. Radiology 254(2):587-594

17. Hrinivich WT, Hoover DA, Surry K, Edirisinghe C, Montreuil J, D'Souza D et al (2016) Three-dimensional transrectal ultrasound guided high-dose-rate prostate brachytherapy: a comparison of needle segmentation accuracy with two-dimensional image guidance. Brachytherapy 15(2):231-239

18. Rogatsch H, Mairinger T, Horninger W, Gschwendtner A, Bartsch G, Mikuz G (2000) Optimized preembedding method improves the histologic yield of prostatic core needle biopsies. Prostate 42(2):124-129

19. Gayet M, van der Aa A, Schmitz P, Beerlage HP, Schrier BP, Mulders PFA et al (2016) 3D Navigo ${ }^{\mathrm{TM}}$ versus TRUS-guided prostate biopsy in prostate cancer detection. World J Urol 34(9):1255-1260

20. Peltier A, Aoun F, El-Khoury F, Hawaux E, Limani K, Narahari $\mathrm{K}$ et al (2009) 3D versus 2D systematic transrectal ultrasoundguided prostate biopsy: higher cancer detection rate in clinical practice. Prostate Cancer 2013(2013):783243

21. Rogatsch H, Moser P, Volgger H, Horninger W, Bartsch G, Mikuz G et al (2000) Diagnostic effect of an improved preembedding method of prostate needle biopsy specimens. Hum Pathol 31(9):1102-1107
22. Epstein JI, Allsbrook WCJ, Amin MB, Egevad LL (2005) The 2005 International Society of Urological Pathology (ISUP) consensus conference on Gleason grading of prostatic carcinoma. Am J Surg Pathol 29(9):1228-1242

23. Epstein JI, Egevad LL, Amin MB, Delahunt B, Sringley J, Humphrey P et al (2016) The 2014 International Society of Urological Pathology (ISUP) consensus conference on Gleason grading of prostatic carcinoma: definition of grading patterns and proposal for a new grading system. Am J Surg Pathol 40(2):244-252

24. Freedland SJ, Kane CJ, Amling CL, Aronson WJ, Terris MK, Presti JC (2007) Upgrading and downgrading of prostate needle biopsy specimens: risk factors and clinical implications. Urology 69(3):495-499

25. Chun FKH, Briganti A, Shariat SF, Graefen M, Montorsi F, Erbersdobler A et al (2006) Significant upgrading affects a third of men diagnosed with prostate cancer: predictive nomogram and internal validation. BJU Int 98(2):329-334

26. Quintana L, Ward A, Gerrin SJ, Genega EM, Rosen S, Sanda MG et al (2016) Gleason misclassification rate is independent of number of biopsy cores in systematic biopsy. Urology 91:143-148

27. Kim KH, Lim SK, Shin TY, Lee JY, Chung BH, Rha KH et al (2013) Upgrading of Gleason score and prostate volume: a clinicopathological analysis. BJU Int 111(8):1310-1316

28. Öbek C, Doanca T, Erdal S, Erdoğan S, Durak H (2012) Core length in prostate biopsy: size matters. J Urol 187(6):2051-2055

29. Burchardt M, Engers R, Müller M, Burchardt T, Willers R, Epstein JI et al (2008) Interobserver reproducibility of Gleason grading: evaluation using prostate cancer tissue microarrays. J Cancer Res Clin Oncol 134(10):1071-1078

30. Kuroiwa K, Shiraishi T, Ogawa O, Usami M, Hirao Y, Naito S (2010) Discrepancy between local and central pathological review of radical prostatectomy specimens. J Urol 183(3):952-957

31. Servoll E, Sæter T, Vlatkovic L, Lund T, Nesland J, Waaler G et al (2012) Impact of a tertiary Gleason pattern 4 or 5 on clinical failure and mortality after radical prostatectomy for clinically localised prostate cancer. BJU Int 109(10):1489-1494

32. Sauter G, Clauditz T, Steurer S, Wittmer C, Büscheck F, Krech $\mathrm{T}$ et al (2017) Integrating tertiary Gleason 5 patterns into quantitative Gleason grading in prostate biopsies and prostatectomy specimens. Eur Urol. https://doi.org/10.1016/j.eururo.2017.01.015 